\title{
A comparative analysis of Mean Platelet Volume in COPD patients vs. healthy controls
}

\author{
Dr. S.Banerjee ${ }^{1}$, Dr. Anshul Kumar ${ }^{2} *$, Dr. Sujata Ganguly ${ }^{2}$, Dr. Ravi Shanker ${ }^{2}$, \\ Dr. Arun Singh ${ }^{3}$,Dr.Abhimanyu Uppal ${ }^{3}$,Dr. Ajay ${ }^{4}$, Dr. Kamlesh ${ }^{4}$ \\ ${ }^{I}$ (Senior Professor and unit head, Department of Medicine, S.M.S. Medical College, Jaipur, Rajasthan, India), \\ ${ }^{2}$ (3rd year Resident Doctor, Department of Medicine, S.M.S. Medical College, Jaipur, Rajasthan, India), \\ ${ }^{3}$ (2rd year Resident Doctor, Department of Medicine, S.M.S. Medical College, Jaipur, Rajasthan, India), \\ ${ }^{4}$ (1st year Resident Doctor, Department of Medicine, S.M.S. Medical College, Jaipur, Rajasthan, India),
}

\begin{abstract}
Mean platelet volume is a marker of inflammation which is found to be increased in patients at risk for atherothrombotic disease and measurement of platelet volume has been suggested as a marker of platelet activation ${ }^{I}$.The association between Mean platelet Volume and chronic obstructive pulmonary disease is controversial

Objective: To determine the difference in mean platelet volume in patients with Chronic Obstructive Pulmonary Disease and healthy age matched controls

Method: This study was conducted in the Department of Medicine, SMS Medical College and Attached hospitals, Jaipur. 55 Patients of COPD diagnosed according to the GOLD's criteria were consecutively enlisted and enrolled from those attending the medicine outdoor and wards. The controls taken were 55 healthy age and sex matched preferably relative of the patient with no history of shortness of breath and normal pulmonary function test.The inclusion and exclusion criteria was applied and both the cases and controls were subjected to various investigations like Complete blood count, Liver function tests, arterial blood gas etc.

Results: It was found in the study that the patients with COPD had raised TLC, S.CRP positivity, Increased platelet count and decreased Mean platelet Volume as compared to the healthy controls.

Conclusion: The study showed that the COPD patients have lower Mean platelet Volume than healthy controls

Keywords: Mean platelet Volume, COPD, Total Leucocyte count
\end{abstract}

\section{Introduction}

Chronic Obstructive Pulmonary Disease (COPD) is a major cause of morbidity and mortality in the world. The global initiative for Chronic Obstructive Lung Disease (GOLD) recently defined COPD as "a common preventable and treatable disease characterized by persistent airflow limitation that is usually progressive and associated with an enhanced chronic inflammatory response in the airways and the lung to noxious particles or gases. Exacerbations and co morbidities contribute to the overall severity in individual patient" (GOLD) $)^{13}$

It has been established that stable COPD is associated with low grade systemic inflammation as demonstrated by an increase in Blood leucocytes, Acute phase proteins such as CRP and inflammatory cytokines $^{15,16,17}$. Epidemiological data suggests that impaired lung function in COPD is strongly related to impaired cardiovascular function and cardiovascular related deaths ${ }^{14}$. In addition, Chronic obstructive pulmonary disease and atherosclerosis often coexists and share common risk factors such as age and smoking. Inflammation plays a key role in the progression of both COPD and atherosclerosis.

Platelets are involved in atherogenesis, inflammation and atherothrombosis. A recent study found that elevation in arginase activity in platelets reflected alterations in Nitric oxide metabolism and enhanced platelet activity in chronic obstructive pulmonary disease ${ }^{18}(\mathrm{COPD})$. Moreover, soluble P Selectin, a marker of platelet hyper reactivity, was reported to be higher in COPD patients. ${ }^{19}$ Previous studies showed inverse correlations between MPV and disease activity in inflammatory bowel disease, rheumatoid arthritis and ankylosing spondylitis ${ }^{23,24}$ Mean platelet volume is a marker of inflammation it is found to be increased in patients at risk for atherothrombotic disease and measurement of platelet volume has been suggested as a marker of platelet activation ${ }^{1}$.

The association between Mean platelet Volume and chronic obstructive pulmonary disease is controversial. Some studies have shown that Stable COPD patients have higher Mean platelet volume than those in the control groups ${ }^{9}$ whereas another report found that this association of increased mean platelet volume in COPD patients was not statistically significant ${ }^{10}$. The conflicting data may be due to the failure to rule out various confounding factors such as body mass index, smoking status and medication use ${ }^{23}$. Obesity and cigarette smoking increase Mean platelet volume and weight loss and smoking cessation decreased Mean 
platelet Volume ${ }^{24,26}$ Medications such as Statins and Angiotensin converting enzyme inhibitors exert anti inflammatory effect in COPD ${ }^{27}$

Despite all the various studies little is known regarding the status of mean platelet volume in COPD. Biljak et al ${ }^{11}$ and $\mathrm{Cui} \mathrm{H}$ et al ${ }^{12}$ had conflicting results. Also, no reliable study has been performed on Indian patients thus, it was deemed worthwhile to study the effect of COPD on mean platelet volume.

Methods: This study was conducted in the Department of Medicine, SMS Medical College and Attached hospitals, Jaipur. 55 Patients of COPD diagnosed according to the GOLD's criteria were consecutively enlisted and enrolled from those attending the medicine outdoor and wards. The controls taken were 55 healthy age and sex matched preferably relative of the patient with no history of shortness of breath and normal pulmonary function test.

Study design: This was a hospital based observational descriptive comparative analysis

Study period: From the approval of plan till when the desired sample size of cases and controls was achieved. Sample size: Sample size was calculated as 54 subjects at $97.5 \%$ confidence interval and $80 \%$ power assuming minimum detectable difference in mean platelet volume of $0.6 \pm 1$ as per the seed article. So, for the purpose of our study we took 55 cases and 55 controls.

\section{Inclusion Criteria}

COPD patients who presented to SMS medical college and hospital Jaipur. COPD was diagnosed and classified according to the Global Initiative for Chronic Obstructive Lung disease criteria)

\section{Exclusion criteria}

1. Haematological disorders,

2. Autoimmune disease,

3. Pneumonia,

4. Active Pulmonary tuberculosis,

5. Cystic Fibrosis,

6. Valvular heart disease

7. Hepatic Failure

8. Heart failure

9. Renal failure

10. Treatment with anticoagulants, statins, ACE inhibitors, Clopidogrel, theophylline in the previous 8 weeks

11. Any other chronic inflammatory condition

12. Cancer patients on Long term Oxygen Therapy

\section{Data collection}

A proforma sheet was prepared to get information on age, sex, occupation, residence. A complete history which included symptoms was taken. Relevant past history, family history, treatment history was taken. Each patient was thoroughly examined and the particulars were noted on the proforma sheet. A comprehensive Respiratory system Examination was undertaken. Other systems were also thoroughly examined with special emphasis on any particular system if it were involved in the disease process.

The following investigations were done in all patients.

- Complete Blood Count Including Mean platelet Volume

- $\quad$ Liver Function Tests

- Renal Function Tests

- Random Blood sugar

- Erythrocyte sedimentation Rate (ESR)

- C Reactive protein

- Arterial Blood Gas analysis

- Pulmonary Function Tests

\section{Statistical analysis:}

The results were obtained and noted in the proforma. All the data was entered on Microsoft Excel Sheet and analysed using SPSS 19.0 statistical software. The quantitative data was summarized as Mean \pm standard deviation and the difference in means was analysed using student ' $t$ ' test. Difference in MPV among COPD and healthy Controls was calculated using student ' $t$ ' Test. Difference in proportion of cases with different levels of MPV in both groups was calculated using chi square test and the Correlation between MPV and various other clinical parameters using ANNOVA and Pearson's coefficient Level of significance i.e. P value $<0.05$ was kept as significant whereas $<0.001$ was kept as highly significant. 
III. Results

Table 1: The clinical characteristics of the cases and controls are shown in

\begin{tabular}{|l|l|l|l|}
\hline Clinical variable & Cases & Controls & P value \\
\hline Number & 55 & 55 & \\
\hline Mean Age (years) & $66.3 \pm 9.8$ & $63.0 \pm 11.7$ & 0.1058 \\
\hline Gender(females\%) & 12.73 & 12.73 & \\
\hline BMI & $22.1 \pm 3.0$ & $22.2 \pm 3.0$ & 0.9067 \\
\hline Smoking (Pack years) & $40.6 \pm 10.0$ & $39.3 \pm 8.3$ & 0.4508 \\
\hline Hypertension & 30 & 30 & \\
\hline $\begin{array}{l}\text { Medication } \\
\text { I. Inhaled bronchodilators }\end{array}$ & 55 & 0 & \\
II. Inhaled corticosteroids & 47 & 0 & \\
\hline Pulse rate(beats/min) & $101.6 \pm 11.6$ & $88.6 \pm 9.5$ & $<0.0001$ \\
\hline Respiratory rate(breaths/min) & $24.9 \pm 5.2$ & $18.9 \pm 3.2$ & $<0.0001$ \\
\hline
\end{tabular}

The clinical characteristics of subjects with stable COPD and controls are reported in Table 1. The groups were well matched with respect to age, gender, body mass index and smoking status. The use of inhaled bronchodilators and inhaled corticosteroid was more prevalent in the COPD group. There was no difference in the proportion of patients with hypertension between the two groups.

Table 2 : The various laboratory characteristics of the cases and the controls

\begin{tabular}{|l|l|l|l|}
\hline Lab characteristics & Cases & Controls & P value \\
\hline FEV1/FVC & $0.5 \pm 0.1$ & $0.9 \pm 0.1$ & $<0.0001$ \\
\hline $\mathrm{PaO} 2(\mathrm{~mm}$ of $\mathrm{Hg})$ & $85.5 \pm 12.6$ & $96.8 \pm 6.9$ & $<0.0001$ \\
\hline $\mathrm{PaCO} 2(\mathrm{~mm}$ of $\mathrm{Hg})$ & $51.1 \pm 11.6$ & $31.7 \pm 6.9$ & $<0.0001$ \\
\hline $\mathrm{TLC}$ & $11.6 \pm 3.7$ & $8.1 \pm 2.1$ & $<0.0001$ \\
\hline $\mathrm{MPV}$ & $9.1 \pm 0.8$ & $9.6 \pm 0.8$ & 0.0007 \\
\hline Platelet count & $307.2 \pm 95.1$ & $272 \pm 71.8$ & 0.0303 \\
\hline Haemoglobin & $12.5 \pm 1.9$ & $11 \pm 2.3$ & 0.2029 \\
\hline
\end{tabular}

The laboratory characteristics of the COPD patients and control are shown in table 2. Significant difference is observed in the pulmonary function parameters (FEV1/FVC) which as seen in the table is significantly less for the COPD group

On comparing the $\mathrm{ABG}$ parameters it is seen that the $\mathrm{pCO} 2$ is increased while the $\mathrm{pO} 2$ is significantly decreased in the COPD group as compared to the control population

A significant difference was also observed between the Total leucocyte count and the platelet count between the two groups both of which were increased in the COPD patients as compared to the controls. A p value for the difference in the TLC was $<00001$ while that for the platelet count is 0.0303 both are significant. It was also observed that the mean platelet volume in the COPD group was significantly lower as compared to the control group with a significant $\mathrm{p}$ Value of 0.0007

\section{Discussion and conclusion}

The main findings of our study are the following: COPD patients have lower MPV as compared to healthy age and sex matched controls. ,

The increased systemic inflammation observed in COPD may be associated with decreased MPV as observed in other conditions ${ }^{5,6}$. A recent metaanalysis has shown that CRP and TNF are important mediators linking the disease to systemic inflammation ${ }^{28}$. Increased pro inflammatory cytokines in COPD are involved in enhanced oxidative stress which contributes to platelet activation .

On the other hand, increased inflammatory cytokines influence megakaryocytopoiesis and platelet volume. ${ }^{29}$ Moreover, platelet aggregation is accelerated by hypercapnia and/or hypoxaemia. ${ }^{30}$

As COPD is an inflammatory condition which explains the presence of increae in TLC, platelet count etc. Cardiovascular disease is one of the common causes of mortality in mild and moderate COPD patients. ${ }^{31,32}$ The prevalence of cardiovascular disease in COPD is related to the coexistence of risk factors including age, obesity, diabetes, smoking and low level of physical activity. ${ }^{33}$

Systemic inflammation may be a mechanism for the development and progression of atherosclerosis in COPD. Multifactorial complex interactions between platelets, endothelial cells and leukocytes further stimulate the production of proinflammatory cytokines and may lead to thrombosis. ${ }^{34}$ Our study showed increased platelet count and decreased MPV in COPD patients. The results indicated that the increased thrombotic risk in COPD might be still induced by the activated platelet. However, our study does not show that the MPV itself is increased as a marker of platelet activation as seen in studies assessing cardiovascular risk factors. Recent studies revealed that high-grade inflammatory diseases are associated with smaller platelets, whereas the same disorders at remission and controlled by anti-inflammatory drugs are associated with larger platelets. ${ }^{35}$ 
The strengths of our study is the presence of well matched controls with respect to their age, sex, BMI and smoking habits by negating the effect that these factors may have on the mean platelet volume.

The main drawbacks of our study are that it is a single centre study compared to the magnitude and the burden of disease the sample size taken was small Follow up study was not done. Patients can be followed and various parameters evaluated in the exacerbated and stable state Various biochemical parameters like S.CRP were not evaluated as quantitative S.CRP is not evaluated in our hospital

\section{Reference}

[1]. Chu SG, Becker RC, Berger PB et al. Mean platelet volume as a predictor of cardiovascular risk: a systematic review and metaanalysis. J. Thromb. Haemost.2010; 8: 148-56.

[2]. Berger JS, Eraso LH, Xie D et al. Mean platelet volume and prevalence of peripheral artery disease, the National Health and Nutrition Examination Survey, 1999-2004. Atherosclerosis 2010; 213: 586-91.

[3]. Muscari A, Puddu GM, CenniA et al. Mean platelet volume (MPV) increase during acute non-lacunar ischemic strokes. Thromb.Res. 2009; 123: 587-91.

[4]. Kisacik B, Tufan A, Kalyoncu U et al. Mean platelet volume (MPV) as an inflammatory marker in ankylosing spondylitis and rheumatoid arthritis. Joint Bone Spine 2008; 75: 291-4.

[5]. Gasparyan AY, Sandoo A, Stavropoulos-KalinoglouA et al. Mean platelet volume in patients with rheumatoid arthritis: the effect of anti-TNF-alpha therapy. Rheumatol.Int. 2010; 30: 1125-9.

[6]. Yuksel O, Helvaci K, Basar O et al. An overlooked indicator of disease activity in ulcerative colitis: mean platelet volume. Platelets 2009; 20: 277-81.

[7]. Braekkan SK, Mathiesen EB, Njolstad I et al. Mean platelet volume is a risk factor for venous thromboembolism: the Tromso Study, Tromso, Norway. J. Thromb. Haemost.2010; 8: 157-62. 1

[8]. Steiropoulos P, Papanas N, Nena E et al. Mean platelet volume and platelet distribution width in patients with chronic obstructive pulmonary disease: the role of comorbidities. Angiology 2012.doi: 10.1177/0003319712461436

[9]. Ulasli SS, Ozyurek BA, Yilmaz EB et al. Mean platelet volume as an inflammatory marker in acute exacerbation of chronic obstructive pulmonary disease. Pol. Arch. Med.Wewn. 2012; 122: 284-90.

[10]. Maclay JD, McAllister DA, Johnston S et al. Increased platelet activation in patients with stable and acute exacerbation of COPD. Thorax 2011; 66: 769-74

[11]. Biljak VR, Pancirov D, Čepelak I, Popović-Grle S, Stjepanović G, Grubišić TŽ. Platelet count, mean platelet volume and smoking status in stable chronic obstructive pulmonary disease. Platelets. 2011 Sep 1;22(6):466-70.

[12]. Hua Cui Lin Liu Zhimin Wei Delong WangYixin Hu Guoliang HuLi Fan.Clinical value of mean platelet volume for impaired cardiopulmonary function in very old male patients with chronic obstructive pulmonary diseaseaggjournalMarch-April, 2012Volume 54, Issue 2, Pages e109-e112

[13]. From the global strategy for the Diagnosis Management and prevention of COPD, Global Initiative for Chronic Obstructive Lung Disease.(2015)

[14]. Sin DD, Wu L, Man SF. The relationship between reduced lung function and cardiovascular mortality: a population-based study and a systematic review of the literature. Chest 2005; 127: 1952-9.

[15]. Vernooy JH, Küçükaycan M, Jacobs JA, et al. Local and systemic in-flammation in patients with chronic obstructive pulmonary disease: soluble tumor necrosis factor receptors are increased in sputum. Am J RespirCrit Care Med. 2002; 166: 1218-1224

[16]. Dev D, Wallace E, Sankaran R, et al. Value of C-reactive protein mea-surements in exacerbations of chronic obstructive pulmonary disease. Respir Med. 1998; 92: 664-667.

[17]. Schols AM, Buurman WA, Staal van den Brekel AJ, et al. Evidence for a relation between metabolic derangements and increased levels of inflam-matory mediators in a subgroup of patients with chronic obstructive pulmo- nary disease. Thorax.1996; 51: 819824 .

[18]. Guzman-Grenfell A, Nieto-Velazquez N, Torres-Ramos Y et al. Increased platelet and erythrocyte arginase activity in chronic obstructive pulmonary disease associated with tobacco or wood smoke exposure. J. Investig. Med. 2011; 59: 587-92.

[19]. Ferroni P, Basili S, Martini F et al. Soluble P-selectin as a marker of platelet hyperactivity in patients with chronic obstructive pulmonary disease. J. Investig. Med. 2000; 48: 21-7.

[20]. Sandhaus LM, Meyer P. How useful are CBC and reticulocyte reports to clinicians? Am J ClinPathol.2002; 118: 787-793.

[21]. Kisacik B, Tufan A, Kalyoncu U, et al. Mean platelet volume (MPV) as an inflammatory marker in ankylosing spondylitis and rheumatoid arthritis. Joint Bone Spine. 2008; 75: 291-294

[22]. Park Y, Schoene N, Harris W. Mean platelet volume as an indicator of platelet activation: methodological issues. Platelets 2002; 13: 301-6.

[23]. Varol E, Icli A, Kocyigit S et al. Effect of smoking cessation on mean platelet volume. Clin. Appl. Thromb. Hemost.2012; 19: 315-

[24]. Yarlioglues M, Ardic I, Dogdu O et al. The acute effects of passive smoking on mean platelet volume in healthy volunteers. Angiology 2011; 63: 353-7.

[25]. Coban E, Ozdogan M, Yazicioglu G et al. The mean platelet volume in patients with obesity. Int. J. Clin. Pract.2005; 59: 981-2

[26]. Coban E, Yilmaz A, Sari R. The effect of weight loss on the mean platelet volume in obese patients. Platelets 2007; 18: 212-6.

[27]. Marin L, Colombo P, Bebawy M et al. Chronic obstructive pulmonary disease: patho-physiology, current methods of treatment and the potential for simvastatin in disease management. Expert Opin.Drug Deliv.2011; 8: 1205-20.

[28]. Gan WQ, Man SF, SenthilselvanA et al. Association between chronic obstructive pulmonary disease and systemic inflammation: a systematic review and a meta-analysis. Thorax 2004; 59: 574-80

[29]. Chuen CK, Li K, Yang M et al. Interleukin-1beta up-regulates the expression of thrombopoietin and transcription factors c-Jun, cFos, GATA-1, and NF-E2 in megakaryocytic cells. J. Lab. Clin. Med. 2004; 143: 75-88

[30]. Wedzich JA, Syndercombe-Court D, Tan KC. Increased platelet aggregate formation in patients with chronic air flow obstruction and hypoxaemia. Thorax 1991; 46: 504-7.

[31]. Anthonisen NR, Skeans MA, Wise RA et al. The effects of a smoking cessation intervention on 14.5-year mortality: a randomized clinical trial. Ann. Intern. Med. 2005; 142: 233-9.

[32]. Pauwels RA, Lofdahl CG, Laitinen LA et al. Long-term treatment with inhaled budesonide in persons with mild chronic obstructive pulmonary disease who continue smoking. European Respiratory Society Study on Chronic Obstructive Pulmonary Disease. N. Engl. J. Med. 1999; 340: 1948-53. 
[33]. Waschki B, Kirsten A, Holz O et al. Physical activity is the strongestpredictorofall-causemortalityinpatientswithCOPD:aprospective cohort study. Chest 2011; 140: 331-42

[34]. Gawaz M, Langer H, May AE. Platelets in inflammation and atherogenesis. J. Clin. Invest. 2005; 115: 3378-84.

[35]. Gasparyan AY, Ayvazyan L, Mikhailidis DP et al. Mean platelet volume: a link between thrombosis and inflammation? Curr. Pharm. Des. 2011; 17: 47-58. 